\title{
Biological significance of hypercalcitoninemia and hypocalcemia in blood under different state of carbohydrate metabolism in ontogenesis of rats
}

\begin{abstract}
The retrospective mini-review contains contemporary literature data about biological importance of change in the blood level of calcitonin under different conditions of carbohydrate metabolism. An increase in calcitonin activity value and a decrease in plasma concentration of total calcium in rats of all age groups were established in hypo- and hyperglycemia. More noticeable hypocalcemia and hyper calcitoninemia in glucose tolerant test and more intensive changes in calcitonin secretion and hypocalcemia in insulin hypoglycemia were detected in immature rats than in adult and old rats. A conclusion was made that biological significance of a rise of calcitonin in different conditions of carbohydrate metabolism was body calcium saving.
\end{abstract}

Keywords: hyper calcitoninemia, hypocalcemia, hypoglycemia, hyperglycemia, carbohydrate metabolism, body calcium saving
Volume 3 Issue I - 2018

\author{
Moisa SS \\ Institute of Biomedical Problems of the Russian Academy of \\ Sciences, Russia
}

\begin{abstract}
Correspondence: Moisa SS, Federal State-Financed Establishment of Science, State Scientific Center of the Russian Federation, Institute of Biomedical Problems of the Russian Academy of Sciences, Moscow, Russia, Email butalana07@list.ru
\end{abstract}

Received: June 16, 2017 | Published: February 08, 2018

\section{Introduction}

It is known that carbohydrate metabolism is connected with calcium metabolism and that some disturbances of calcium metabolism can play the definite role in the pathogenesis of diabetes mellitus., ${ }^{1,2}$ The changing of insulin secretion was found under hypo-and hyperparathyroidism, ${ }^{3}$ hypocalcemia, induced by parathyroidectomy, ${ }^{4}$ primary hyperparathyroidism with hyper calcemia. ${ }^{5}$ The prevalence of diabetes mellitus in patients with primary hyperparathyroidism after operation is higher than in control. ${ }^{6}$ Intracellular $\mathrm{Ca}^{2+}$ plays a key role in metabolic disorders associated with obesity and insulin resistance. ${ }^{7}$ Calcium sediment in bone, its absorption in intestine is decreased and calcium excretion with urine is increased in men and rats under diabetes mellitus. ${ }^{8-10}$ Total calcium content in the blood serum in patients with diabetes mellitus are in norm, ${ }^{11,12}$ at that ionizing calcium concentration is decreased,,$^{13}$ moreover in children till 16 years old the differences are the most significant in comparison with healthy persons. ${ }^{11}$ Disturbances of carbohydrate metabolism can also act on calcium metabolism not only in adult individuals, but and in their posterity. Thus, in rats (female) with diabetes mellitus and reduced mass there are some disorders in fetus structure skeleton and delays of skeleton development in kind of the decreasing of skeleton calcification and reducing calcium content in kidney, liver, serum, placenta. ${ }^{14}$ It is suggested that reduced calcium level can promote to the development of the disorders of bone tissue under diabetes mellitus. ${ }^{11}$ Moreover, it is established the increasing of $\mathrm{Ca}$ and $\mathrm{P}$ excretion with urine under the metabolic syndrome, what positively correlated with the glycemia and the insulin level in blood ${ }^{15}$ and the intensification of bone restoration, that it is connected with the disturbance of Ca-P metabolism and the secretion of calciumregulating hormones: calcium-reducing hormone-calcitonin $(\mathrm{CT})$ and calcium-increasing hormone - parathyroid (PTH) ${ }^{16}$ On the other hand, the disturbances of carbohydrate and lipid metabolism were revealed under the primary hyperparathyroidism. ${ }^{17}$ Some authors ${ }^{12,18}$ consider that negative calcium balance under diabetes mellitus happens because of metabolic disturbances due to insulin deficiency. This fact is worth of taking into account as far as just recently it was discussed about CT participant in the development of insulin resistance. ${ }^{19}$ The shifts in neuroendocrine regulation of glucose metabolism, in one's turn, are indifferent for the secretion of calcium-regulating hormones. The increasing of CT and PTH secretion was established in patient with the primary manifested diabetes mellitus, ${ }^{1}$ and the decreasing of calcium and PTH concentration and the increasing of CT level in blood were discovered in healthy persons to an answer on glucose load. ${ }^{20}$ In healthy persons in 90-240minutes after glucose load the increasing $\mathrm{CT}$ level is revealed in hypoglycemic phase. ${ }^{21}$

\section{Calcitonin secretion is under different state of carbohydrate metabolism}

As it is occurred, the blood glucose level is indifferent to the reactivity of $\mathrm{C}$-cells of thyroid gland. Thus, in our previous investigations it was established the increasing of calcitonin-activity (CT-activity) and the decreasing of the total serum calcium level in rats Wistar immature, adult and old age under insulin hypoglycemia $(\mathrm{IH})$, and glucose tolerance test (GTT) ${ }^{22,23} \mathrm{IH}$, induced with insulin injection (1 IU/100g). 2hours after insulin administration blood samples from the femoral vein were taken in rats under the light ether anesthesia. 30\% glucose solution ( $1 \mathrm{ml} / 100 \mathrm{~g}$ body weight) animals received per os on an empty stomach and then blood samples were taken every 30minutes (30-240min) after glucose load under the light ether anesthesia. For evaluation of hypoglycemia or hyperglycemia degree the blood glucose level was measured by the colorimetric method of Frank-Kirberger. ${ }^{24}$ To assess the state of CT secretion we determined CT-activity using the method of Laljee ${ }^{25}$ with the help of salmon CT as standard (method of biological test). The total calcium content was assayed by complexion-metric method. ${ }^{26}$ For biological test were used 190mice. The data processed statistically using Student-Fisher tests.

Hypercalcitoninemia and hypocalcemia are revealed both under hypo- and hyperglycemia. Moreover, more noticeable hypocalcemia and hypercalcitoninemia in GTT and more intensive changes in 
CT secretion and hypocalcemia in $\mathrm{IH}$ were detected in immature rats than in adult and old rats. In our opinion, the most expressed hypocalcemia in immature animals has a biological significance as far as it promotes to calcium saving and reserving in organism and plays the role in adaptation of organism, especially, growing one, for which the exhaustion of calcium stock is the most important for the growth and development.

\section{Calcitonin secretion is under insulin hypoglycemia}

Significant decreasing of the blood glucose level is, as it is known, powerful stressor. The development of stress is accompanied by the intensification of CT secretion and hypocalcemia. ${ }^{27}$ Therefore, the increasing of CT secretion under IH is protective mechanism, limiting the expression of stress reaction, and it is the adaptive reaction of organism, directed to body calcium saving. Thus, the inhibition of insulin secretion, the increasing of glucagon secretion and processes of glycogenolysis and gluconeogenesis under CT effect, on the one hand, induce together with other sugar-increasing hormones glucose release, providing the brain necessary energetic material. On the other hand, it should note especially, that for the compensation of energy expense, connected with "acute stress", CT (as well with glucagon, adrenalin, glucocorticoids, somatotropin) evokes free fatty acids release. As it is known, stress phylogenetically connected with muscle work, so it isn't interest some facts about the increasing of CT-activity and the decreasing of calcium level in the blood serum of men and laboratory animals under muscle load. ${ }^{28}$ Glucose content under muscle work quickly soon falls as a result of their fast outlay and realizing free fatty acids can use by the muscles as energy recourse. CT-activity value and hypocalcemia degree under $\mathrm{IH}$ are expressed more in immature rats, than in adult and old ones. This circumstance can be explained with increasing energy needs of the growing organism and has important significance in the adaptation of organism, especially growing, for which significant decreasing of glucose level the main energetic recourse is the most dangerous. The increasing of CT secretion under IH is non-specific answer to the effect of the stressor (insulin hypoglycemia), which biological importance is determined by the following:

I. CT and the decreasing of extracellular calcium concentration inhibit secretion of endogenous insulin - the main sugardecreasing hormone and this way prevent organism from excess decreasing of the blood glucose level $;{ }^{29-31}$

II. CT intensifies the secretion of endogenous glucagon; ${ }^{23}$

III. CT stimulates gluconeogenesis ${ }^{32}$ and glycogenolysis; $;^{33}$

IV. CT increases the secretion of sugar-increasing hormones catecholamine's and cortisol; ${ }^{34}$

V. CT has hyperglycemic effect; ${ }^{31,35,36}$

VI. CT increases the concentration of free fatty in blood. ${ }^{37}$

\section{Calcitonin secretion is under glucose tolerant test}

Under GTT in rats of all age groups the increasing of CT-activity and the decreasing of total serum calcium level was established. ${ }^{23,29,38,39}$ One can suppose that hypocalcemia is connected with glucose ability to effect on calcium metabolism, increasing its accumulation in tissues due to the enhancing of calcium entry in cells ${ }^{40}$ or insulin ability to decrease calcium concentration ${ }^{41}$ and increase calcium transport in cells. ${ }^{42}$ Accumulation of intracellular calcium in thyroid gland tissue leads to the enhancing of $\mathrm{CT}$ secretion ${ }^{43}$ that promotes to the further progression of hypocalcemia. It isn't except and direct effect of increasing glucose concentration on C-cells of the thyroid gland, as far as, it is shown, that glucose treatment to thyroidectomized little rats didn't change the blood calcium concentration. ${ }^{39}$ The decreasing of calcium concentration in the blood serum, and also the changing of the functional activity of C-cells of the thyroid gland, on Zoloev's opinion, ${ }^{20}$ can have the definite biological importance. The author considers that the increasing of the blood glucose concentration promotes to the enhancing of insulin level and simultaneously decreasing of calcium content. In one's turn, hypocalcemia weakens glucose effect on pancreas $\beta$-cells, ${ }^{44}$ and insulin promotes to the decreasing of glycemia level. As the result of both processes the excessive secretory activity of pancreas $\beta$-cells decreases and at that in peculiar form mechanism of feedback between glucose, calcium and insulin secretion realizes. Besides, we think that the increasing of CT secretion under hyperglycemia, induced by Per os glucose load, has significance in calcium saving for organism. Revealing their main hypocalcemia effect, CT inhibits bone resorption and calcium absorption by bone tissue and at that calcium excretion with urine decreases. Taking into account the fact that enhanced CT level in the blood serum was discovered in patients with the primary revealed manifest diabetes mellitus ${ }^{1}$ and correlation between the speed of calcium excretion with urine and hyperglycemia degree was established ${ }^{45}$ these data is worth of intent attention and give the basis for the further investigations of the role of hormonal homeostasis in the regulation of calcium and carbohydrate metabolism.

Aging differences of the dynamic of hypocalcemia and CT secretion under glucose load, probably, are connected with that par follicular cells of the thyroid gland in immature rats are more sensitive to the action of the enhancing glucose concentration than in adult and old rats. As far as the exhaustion of calcium stock is the most important for the growth and development of youth organism, this aging peculiarity has common biological significance for the saving of plastic resources. Schematic diagram (below) demonstrates common biological significance of hypercalcitoninemia and hypocalcemia in blood under the different states of carbohydrate metabolism (Figure $1)$.

\section{HYPOGLYCEMIA (IH)}

\section{$\downarrow$}

\section{Hxpercalcitoninemia (†CT secretion) \{\}$\rightarrow$ BODY CALCIUM SAVING}

\section{Hypocalcemia (Lthe total serum calcium level)}

$\uparrow$

\section{HYPERGLYCEMIA (GTT)}

Figure I Demonstrates common biological significance of hypercalcitoninemia and hypocalcemia in blood under the different states of carbohydrate metabolism.

\section{Conclusion}

Thus, under different conditions of carbohydrate metabolism (hypo- and hyperglycemia) are noticed the increasing of CT level and 
the decreasing of the total calcium concentration, the main significance of which is concluded in calcium saving for organism, that is realizes due to the increasing of CT secretion. Moreover, proportion of neuroendocrine regulation of calcium homeostasis in the adaptation to the change of the blood glucose content is not equal in the different age periods and characterizes aging peculiarities.

\section{Acknowledgements}

None.

\section{Conflict of interest}

Author declares that there is no conflict of interest.

\section{References}

1. Mosin VI, Yagoda AV, Grossman BE. Parathormone, calcitonin and cyclic adenosine-mono-phosphate content in blood under diabetes mellitus. Therapeut. 1980;52(8):80-83.

2. Moisa SS, Nozdrachev AD. Mechanisms of calcium and carbohydrate metabolism regulation. GmbH \&Co KG Saarbrucken, Germany: LAP LAMBERT Academic Publishing; 2011.

3. Torella R, Giugliano D, Improta L, et al. Somatostatin and insulin secretion in man. IV. The role of calcium. J Clin Endocrinol Metab. 1980;51(6):1298-1302.

4. Salvesen HA. A note on the relation of the parathyroids to carbohydrate metabolis. Acta Endocrinol (Copenh). 1954;16(4):349-354.

5. Kim H, Kalkhoff RK, Costrini NV, et al. Plasma insulin disturbances in primary hyperparathyroidism. J Clin Invest. 1971;50(12):2596-2605.

6. Ljunghall S, Palmer M, Akerstrom G, et al. Diabetes mellitus, glucose tolerance and insulin response to glucose in patients with primary hyperparathyroidism before and after parathyroidectomy. Eur J Clin Invest. 1983;13(5):373-377.

7. Byyny RL, Loverde M, Llotd S, et al. Cytosolic calcium and insulin resistance in elderly patients with essential hypertension. Am J Hypertens. 1992;5(7):459-464.

8. Dixit PK, Stern AMK. Effect of insulin on the incorporation of citrate and calcium into the bones of alloxan-diabetic rats. Calcified Tissue Res. 1979;27(3):227-232.

9. Witt MF, White NH, Santiago JV, et al. Use of oral calcium loading to characterize the hypercalciuria of young insulin-dependent diabetics. $J$ Clin Endocrinol. 1983;57(1):94-100.

10. Wood RJ, Allen LH, Bronner F. Regulation of calcium metabolism in streptozotpcin-induced diabetes. AmerJPhysiol. 1984;247(1-2):120-123.

11. Fogh Andersen N, Mc Nair P, Moller Petersen J, et al. Lowered serum ionized calcium in insulin treated diabetic subjects. Scand. J Clin Lab Invest. 1983;165:93-97.

12. Ahmedova ZG, Dzhebrailbeily NS. The investigation of the total and ionized calcium level in patients with diabetes mellitus in elderly age. Azerb Med J. 1985;2:59-61.

13. Hui Siu L, Epstein S, Johnston C Conrad. A prospective study of bone mass in patients with type I diabetes. $J$ Clin Endocrinol Metab. 1985;60(1):74-80.

14. Urin Habe JY, Stern JS, Reaven GM, et al. The effect of maternal diabetes on trace element status and fetal development in the rat. Diabetes. 1985;34(10):1031-1040.

15. Belych OA, Geltser BI, Kochetkova EA. Condition of Ca-P metabolism in young women with metabolic syndrome. Far-East Med J. 2006;1:54-58.
16. Belych OA. Functional metabolic mechanisms of remodelizing of bone tissue in young women with dishormonalpatholohy. Russia; Amursk State Medical Academy: 2006.

17. Voronenko IV, Mokrysheva, NG, Rozhinskaja, L Ya. Disturbances of carbohydrate and lipid metabolism under the primeryhyperthyriosis. Obesmetab. 2008;4:18-24.

18. Ishida H, Seino Y, Nishi S, et al. Effects of insulin on altered mineral and vitamin D metabolism in streptozotocin-induced diabetes. Acta endocrinol. 1985;108(2):231-236.

19. Moisa SS. Calcitonin Participant in the Development of Insulin Resistance Journal of Biological Science \& Engineering. 2017;10(7):343-354.

20. Zoloev GK, Slepushkin VD, Yakovleva RA, et al. Interrelation between two-Valent cations, function of pancreas insular apparatus and calciumregulati006Eg hormones under the change of blood glucose content. Human Physiology. 1984;10(3):450-453.

21. Heynen G, Franchimont P. Human calcitonin radioimmunoassay in norma and pathological condition. Europ J Clin Invest. 1974;4(3):213-222.

22. Moisa SS, Nozdrachev AD. Calcitonin secretion under insulin hypoglycemia. OJEMD. 2014;4(11):231-237.

23. Moisa SS. Mechanisms of calcium and carbohydrate metabolism regulation. Autoreferat diss. St.-Petersburg State University, Russia; 2011.

24. Frank H, Kirberger E. Eine Kolorimetrische Methode zur Bestimmung der "Wahren Glucose" und Galactose in $0.005 \mathrm{rm}^{3}$. Blut Biochem Ztschr. 1950;320:359-367.

25. Laljee, HCK, Smith KI, Dorrington KJ. The Assay of Human Thyrocalcitonin in Mice. J Endocrinol. 1967;39(4):507-516.

26. Selochnik II, Briskin AI, Antonova EE. Photoelectrocolorimetric Assay of Calcium Concentration in Serum by the Help of EDTA and Murexide. Chemical Pharmacological Journal. 1978;12:138-140.

27. Drzhevetskaya IA, Mishina NF. Thyrocalcitonin participant in stress development. Physiol J USSR. 1978;64(6): 864-868.

28. Limanskii NN. Interrelation of calcitonin and hormones of hypothalamushypothesis-ardent-cortex system under muscle work. Russia; Moscow State Pedagogical Institute: 1981.

29. Ziegler R, Bellwinkel S, Schmidtchen D, et al. Effects of Hypercalcemia, hypocalcemia and calcitonin on glucose stimulated insulin secretion in man. Horm Metab Res. 1972;4:1-60.

30. Drzhevetskii Yu M, Poliak RI, Briskin AI. Effect of one-time and longlasting injection of thyrocalcitonin on glucose tolerance and insulin secretion. Physiol J USSR. 1976;62(5):762-767.

31. Moisa SS. Contra-insulin effect of calcitonin on glucose metabolism. Bull Exp Biol Med. 2013;156(8):183-185.

32. Yamaguchi M. Calcitonin stimulates gluconeogenesis in fasted rats Endocrinol Jpn. 1981;28(1):51-57.

33. Butakova, Nozdrachev AD. Mechanisms of Hyperglycemic Effect of Calcitonin. Bull Exp Biol Med. 2011;150(3):320-323.

34. Moore $\mathrm{MC}$, Lin $\mathrm{DW}$, Colburn $\mathrm{CA}$, et al. Insulin-and glucagonindependent effects of calcitonin gene-related peptide in the conscious dog. Metabolism. 1999;48(5):603-610.

35. Young AA, Wang MW, Gedulin B, et al. Diabetogenic effects of salmon calcitonin are attributable to amylin-like activity. Metab Clin Exp. 1995;44(12):1581-1589.

36. Butakova Moisa SS, Nozdrachev AD. Effect of one-time injection of calcitonin prepations on glucose and calcium level in rats of different age groups. Adv Gerontol. 2010;23(1):93-97. 
37. Yamaguchi M, Momose K, Takahashi K. Stimulatory effect of calcitonin on fatty acid synthesis in the liver of fed rats. Horm. Metab Res. 1985;17(7):346-350.

38. Yamaguchi M, Yamamoto T. Effects of insulin and calcitonin on the levels of serum calcium and glucose in rats. Chem Pharm Bull. 1977;25(10):2785-2787.

39. Cooper CW, Obie JF. Hypocalcemia and increased serum calcitonin in baby rats given glucose orally. Proc Soc Exp Biol Med. 1978;157(3):374-377.

40. Hellman B, Gylfe E, Berggren PO, et al. $\mathrm{Ca}^{2+}$ transport in pancreatic ß-cells during glucose stimulation of insulin secretion. Upsala J Med Sci. 1980;85(3):321-329.
41. Hollo I, Gero L, Szalay F, et al. Insulin-glucagon and calcitonin-induced early decrease in serum calcium. Hormone Metab Res. 1979;11(1):72-76.

42. Etsuko H, Masahiro N, Kohjiro U, et al. Regulation of calciumpermeable TRPV2 channel by insulin in pancreatic ß-sells. Diabetes. 2009;58(1):174-184.

43. Cooper CW, Ramp WK, Becker DI, et al. In vitro secretion of immunoreactive rat thyrocalcitonin. Endocrinology. 1977;101(1):304-311.

44. Witzel DA, Littledike ET. Suppretion of insulin secretion during induced hypocalcemia. Endocrinology. 1973;93(4):761-766.

45. Sato T, Ohashi M, Yamamoto M, et al. Studies on osteopathy in patients with diabetes mellitus. J Jap Diabet Soc. 1983;26(9):921-930. 